\title{
What Drives the North Atlantic Oscillation's Temperature Anomaly Pattern? Part II: A Decomposition of the Surface Downward Longwave Radiation Anomalies ${ }^{\mathscr{O}}$
}

\author{
JosePh P. Clark AND STEVEn B. FeldSTEIN \\ Department of Meteorology and Atmospheric Science, The Pennsylvania State University, University Park, Pennsylvania
}

(Manuscript received 7 February 2019, in final form 18 August 2019)

\begin{abstract}
Radiative transfer calculations are conducted to determine the contribution of temperature and water vapor anomalies toward the surface clear-sky downward longwave radiation (DLR) anomalies of the NAO. These calculations are motivated by the finding that the NAO's skin temperature anomalies are driven primarily by changes in surface DLR. The clear-sky radiative transfer calculations follow the result that the clear-sky surface DLR anomalies can account for most of the all-sky surface DLR anomalies of the NAO. The results of the radiative transfer calculations prompt an analysis of the thermodynamic energy and total column water (TCW) budget equations, as water vapor and temperature anomalies are found to be equally important drivers of the surface DLR anomalies of the NAO. Composite analysis of the thermodynamic energy equation reveals that the temperature anomalies of the NAO are wind driven: the advection of climatological temperature by the anomalous wind drives the NAO's temperature anomalies at all levels except for those in the upper troposphere-lower stratosphere where the advection of anomalous temperature by the climatological wind becomes dominant. A similar analysis of the TCW budget reveals that changes in TCW are driven by water flux convergence. In addition to determining the drivers of the temperature and TCW anomalies, the thermodynamic energy and water budget analyses reveal that the decay of the temperature anomalies occurs primarily through vertical mixing, and that of the water anomalies mostly by evaporation minus precipitation.
\end{abstract}

\section{Introduction}

An analysis of the surface energy balance was conducted in Clark and Feldstein (2019, hereafter Part I) to determine what drives the skin temperature anomaly pattern associated with the North Atlantic Oscillation (NAO), one of the most dominant atmospheric teleconnection patterns observed in the Northern Hemisphere (e.g., Wallace and Gutzler 1981; Benedict et al. 2004; Franzke et al. 2004; Rivière and Orlanski 2007; Woollings et al. 2008). It was determined, from an analysis of each term in the surface energy balance equation, that the skin temperature anomaly pattern of the NAO (which is characterized by four pronounced anomalies that overlie Greenland, Europe, the United States, and North Africa) is driven primarily by surface downward longwave radiation (DLR), with surface sensible and

Supplemental information related to this paper is available at the Journals Online website: https://doi.org/10.1175/JAS-D19-0028.s1.

Corresponding author: Joseph P. Clark, juc414@psu.edu latent heat fluxes also playing a role over the ocean. This result is consistent with previous studies on NAO events associated with Ural blocks (e.g., Gong and Luo 2017; Luo et al. 2017, 2019), which, like the NAO events discussed in Part I, are associated with high-latitude surface DLR anomalies. However, the question of what causes the surface DLR anomalies associated with the NAO is largely unanswered. While it is known that surface DLR anomalies can arise from changes in cloud cover (liquid water and ice), atmospheric temperature, and water vapor concentration, the contribution of anomalies in each of these variables toward the surface DLR anomalies remains uncertain.

Conceptually, one can understand how cloud fraction, atmospheric temperature and water vapor anomalies independently contribute to surface DLR anomalies by considering a Reynold's decomposition of the quantity $\varepsilon \sigma T^{4}$, which can be taken to represent the surface DLR beneath an idealized single-layer isothermal and homogeneous atmospheric column with temperature $T$ and emissivity $\varepsilon$, where $\sigma$ denotes the StefanBoltzmann constant. Letting the subscript $M$ denote a time average and $\Delta$ the deviation therefrom, the 
surface DLR anomaly beneath this idealized atmospheric column can be written as

$$
\begin{aligned}
\Delta F_{\mathrm{LW}}^{\downarrow}= & \varepsilon \sigma T^{4}-\left[\varepsilon \sigma T^{4}\right]_{M}=\Delta \varepsilon\left[\sigma T^{4}\right]_{M}+\varepsilon_{M} \Delta\left[\sigma T^{4}\right] \\
& +\Delta \varepsilon \Delta\left[\sigma T^{4}\right]-\left\{\Delta \varepsilon \Delta\left[\sigma T^{4}\right]\right\}_{M} .
\end{aligned}
$$

Therefore, according to (1), the surface DLR anomalies $\Delta F_{\mathrm{LW}}^{\downarrow}$ beneath an idealized single-layer atmospheric column can be caused by 1) emissivity anomalies $\Delta \varepsilon$ that interact with the climatological atmospheric temperature $\left[\sigma T^{4}\right]_{M}$, 2) atmospheric temperature anomalies $\Delta\left[\sigma T^{4}\right]$ that interact with the climatological emissivity $\varepsilon_{M}$, and 3) a nonlinear term representing the interaction between the emissivity anomalies $\Delta \varepsilon$ and atmospheric temperature anomalies $\Delta\left[\sigma T^{4}\right]$. For this idealized homogeneous atmospheric column, cloud fraction and water vapor anomalies contribute to $\Delta \varepsilon$ whereas atmospheric temperature anomalies contribute to $\Delta\left[\sigma T^{4}\right]$.

Although a Reynold's decomposition of the surface DLR anomalies is complicated by the fact that the real atmosphere is not homogeneous or isothermal, one can consider the atmosphere to be composed of many shallow homogeneous isothermal layers, indexed $i$, with emissivity $\varepsilon_{i}$ and temperature $T_{i}$, for which the emission of DLR from each individual atmospheric layer is approximately $\varepsilon_{i} \sigma T_{i}^{4}$. Then the surface DLR anomalies below the atmosphere can be decomposed similarly to (1), following a Reynold's decomposition of each individual atmospheric layer $i$. Therefore, although (1) strictly applies to surface DLR anomalies below an idealized atmospheric column, (1) can be conceptually used to understand the surface DLR anomalies below the atmosphere.

The role that emissivity has on altering the surface DLR over the Arctic has been investigated in many previous studies, from which it has been shown that poleward moisture fluxes play a prominent role (e.g., Woods et al. 2013; Woods and Caballero 2016). These moisture fluxes have also been connected to Arctic amplification (e.g., Gong et al. 2017) and sea ice decline (e.g., Francis and Hunter 2006; D-.S. R. Park et al. 2015; H-.S. Park et al. 2015; Gong and Luo 2017; Woods and Caballero 2016) through changes in surface DLR. However, while many previous studies qualitatively examine the role that changes in emissivity have on surface DLR over the Arctic, relatively few studies conduct a full, quantitative treatment of the radiative transfer, perhaps because radiative transfer calculations can be computationally cumbersome.

To quantitatively determine the contribution from changes in clouds, atmospheric temperature, and water vapor to surface DLR anomalies, radiative transfer calculations are necessary. As an example of this approach, in the recent study of Sokolowsky et al. (2019, manuscript submitted to J. Climate), they used the Rapid Radiative Transfer Model (RRTM; Mlawer et al. 1997) to ascertain the contributions from all three phases of water and atmospheric temperature to changes in surface DLR at Barrow, Alaska (now known as Utqiagivik). Although for a region outside that directly impacted by the NAO, the radiative transfer calculations conducted by Sokolowsky et al. (2019, manuscript submitted to J. Climate) indicate that the contributions to changes in surface DLR by atmospheric temperature, water vapor, liquid water, and ice are similar during intrusions of warm, moist air.

To more fully understand the contribution to the NAO's surface DLR anomaly pattern by temperature and emissivity anomalies, in this study, we conduct radiative transfer calculations using RRTMG (Iacono et al. 2008), which is an updated version of RRTM that is utilized in the European Centre for Medium-Range Weather Forecasts (ECMWF) reanalysis model. It should be noted that RRTMG is faster than RRTM and, in this study, it is utilized to conduct radiative transfer calculations globally (i.e., at all grid points) and daily with the aim to determine the drivers of the NAO's surface DLR anomalies. These extensive radiative transfer calculations are complemented by an examination of the thermodynamic energy and total column water (TCW) budget equations associated with the NAO, in order to glean further insights into the physical processes that give rise to the atmospheric temperature and emissivity anomalies that drive the surface DLR anomalies of the NAO, and therefore the NAO's skin temperature anomalies.

As discussed in Part I, the surface air temperature anomalies (at the lowest level of the ECMWF reanalysis model) associated with the NAO are driven by the advection of the climatological temperature field by the anomalous wind field, consistent with presumptions based on sea level pressure anomaly maps (e.g., Walker and Bliss 1932; van Loon and Rogers 1978; Rogers and van Loon 1979; Wallace and Gutzler 1981; Watanabe 2004; Woollings et al. 2008), and decay largely due to longwave radiative heating/cooling. However, because the entire atmospheric temperature profile contributes to DLR anomalies at the surface, the results of Part I are not enough to understand the role that atmospheric temperature anomalies have on the NAO's surface DLR anomaly pattern. To assess the role that atmospheric temperature anomalies have on the NAO's surface DLR anomaly pattern, it is necessary to consider not only surface air temperature anomalies, but also temperature anomalies that develop throughout the depth of 
the entire atmosphere. Therefore, in this study, we extend the thermodynamic budget analysis of Part I to include an examination of temperature anomalies throughout the depth of the entire troposphere and lower stratosphere.

This manuscript is organized as follows. Section 2 documents the data and methods used in this study, including an overview of the radiative transfer calculations that are conducted and a summary of the budget equations that are used. Section 3 contains the results, including a decomposition of the relative roles of water vapor, temperature, and clouds toward the DLR anomalies of the NAO and an analysis of the thermodynamic energy and TCW budgets. A summary of the main conclusions is provided in section 4 .

\section{Data and methods}

For this study, data from the ECMWF interim reanalysis (ERA-Interim; Dee et al. 2011) and the Japanese 55-year Reanalysis (JRA-55; Kobayashi et al. 2015) are utilized from 1979 to 2012 on a $2.5^{\circ} \times 2.5^{\circ}$ grid with a focus on the winter months of December-February (DJF), the season in which the NAO is most active (e.g., Barnston and Livezey 1987). Daily (0000 UTC) data are used for the thermodynamic energy budget analysis, whereas 6-hourly data are used for the TCW budget analysis. Unless stated otherwise, all quantities examined in this study are deseasonalized by subtracting the first 10 harmonics of the calendar-day mean. This includes 6-hourly data, for which a different seasonal cycle is defined for and subtracted from 0000, 0600, 1200, and 1800 UTC. All composites shown in this study use the same NAO events that are discussed in Part I.

\section{a. Radiative transfer calculations}

To determine the contributions that water vapor and temperature anomalies have on the NAO's surface DLR anomaly pattern, radiative transfer calculations are conducted with RRTMG (Mlawer et al. 1997; Iacono et al. 2008) under clear-sky conditions. The clear-sky surface DLR is defined as the surface DLR that would result if there were no clouds, but with the atmospheric temperature profile and concentration of all gases remaining the same. Clouds are neglected from our radiative transfer calculations because, as we will show, the clear-sky surface DLR can account for most of the all-sky (clouds included) surface DLR (Fig. 1).

To isolate the role of water vapor and temperature anomalies toward the surface clear-sky DLR anomalies, we conduct two types of RRTMG experiments. The aim of the first experiment with RRTMG is to determine the impact of anomalies in radiatively active gases (primarily water vapor; see online supplemental material) on surface DLR. For this purpose, we calculate

$$
\operatorname{RRTMG}(g, \bar{T})-\operatorname{RRTMG}(\bar{g}, \bar{T}),
$$

where overbars denote the smoothed seasonal cycle and the quantities $g$ and $T$ are inputs into RRTMG that respectively represent the concentrations of radiatively active gases and the atmospheric temperature profile. All quantities inputted into RRTMG are taken from 0000 UTC ERA-Interim data in the model hybrid sigma-pressure coordinate system. More details about how RRTMG is initialized is included in section 1 of the supplemental material. As a final step, (2) is deseasonalized and then composited based on the NAO events of Part I.

An analogous experiment is conducted to determine the role that atmospheric temperature anomalies have on the clear-sky surface DLR anomalies of the NAO:

$$
\operatorname{RRTMG}(\bar{g}, T)-\operatorname{RRTMG}(\bar{g}, \bar{T}),
$$

where, again, this difference is deseasonalized and composited for the NAO events of Part I. The clear-sky surface DLR [i.e., RRTMG $(g, T)$ ] is also calculated using RRTMG, and the results are deseasonalized and composited. Extensive comparisons indicate that our clear-sky calculations using RRTMG are an excellent match with the ERA-Interim accumulated clear-sky surface DLR data (Figs. S1-S3 in the online supplemental material; note also the similarity between Fig. 1, second row, and Fig. 2, first row).

\section{b. The thermodynamic energy equation}

As noted earlier, to better understand the contribution to the surface DLR anomalies by atmospheric temperature anomalies at all levels in the atmosphere, it is helpful to examine the thermodynamic energy budget (here in pressure coordinates; e.g., Holton and Hakim 2013, p. 69),

$$
\frac{\partial T}{\partial t}=-\mathbf{u} \cdot \nabla T+S_{p} \omega+\frac{\dot{Q}}{c_{p}}+\text { Res },
$$

where $\mathbf{u}, T$, and $\omega$ are horizontal wind, temperature, and vertical velocity $\left(\mathrm{Pa} \mathrm{s}^{-1}\right)$, respectively. The parameter $S_{p} \equiv-(T / \theta)(\partial \theta / \partial p)$ denotes static stability, where $\theta$ is potential temperature and $p$ is pressure; $\dot{Q}$ is diabatic heating and Res is a residual that represents horizontal diffusion (which is included in the reanalysis model, but not in the model output), numerical error, and an analysis increment (e.g., Trenberth et al. 2011). The gradient operator acts only horizontally along constant pressure surfaces. 


\section{ERA Interim: Downward Longwave Radiation Anomalies}
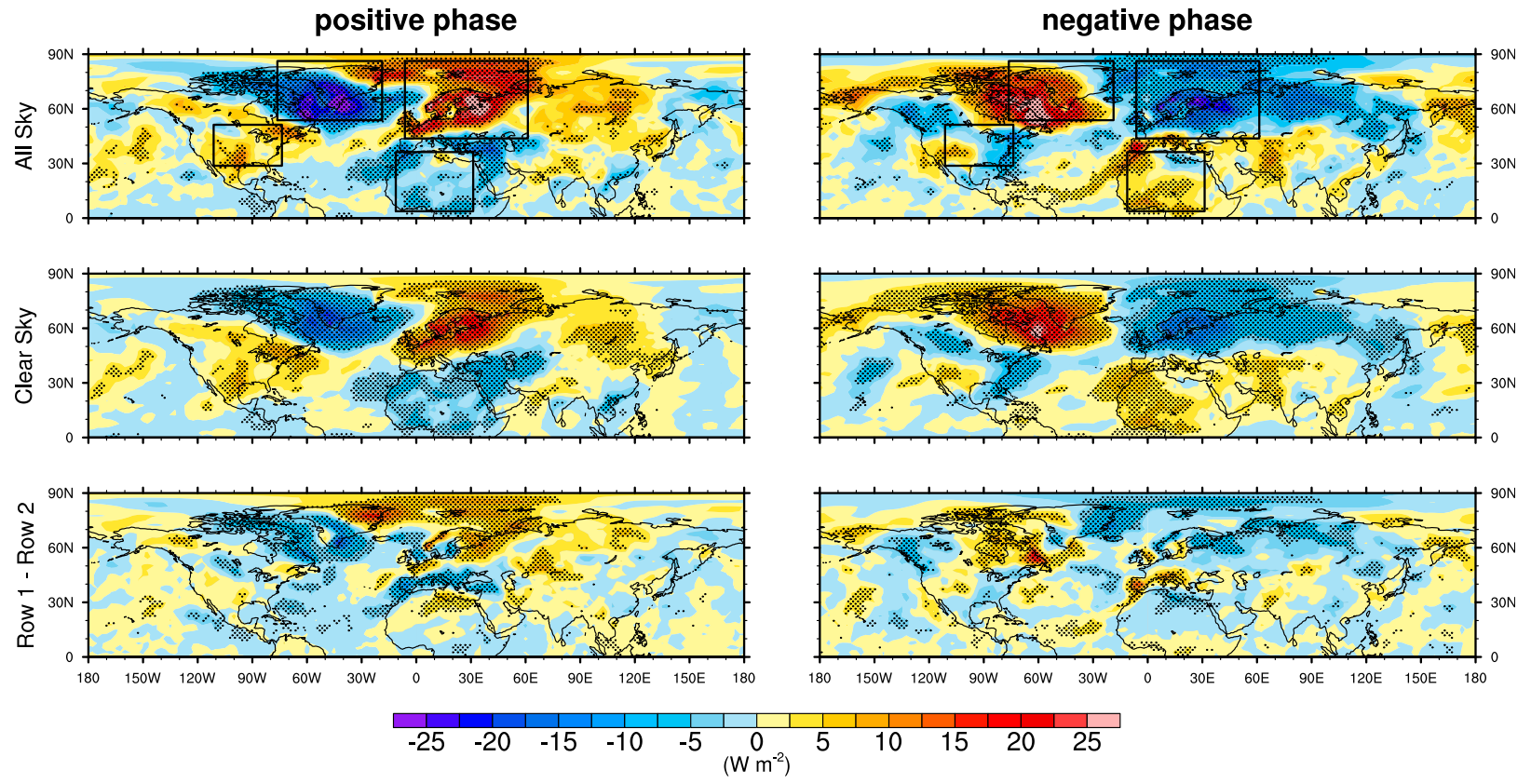

FIG. 1. Composites of (top) surface all-sky downward longwave radiation anomalies and (middle) surface clear-sky downward radiation anomalies for the (left) positive and (right) negative phases of the NAO. (bottom) The top row minus the middle row. All quantities are taken from ERA-Interim. Stippling denotes statistical significance at $p<0.10$. The clear-sky downward longwave radiation is determined by subtracting the net all-sky surface longwave radiation from the net clear-sky longwave radiation, and then adding to the result the allsky downward longwave radiation, using the property that, at the surface, the upward clear-sky longwave radiation is equal to the upward all-sky longwave radiation.

Each term on the right-hand side (rhs) of (4) is computed with daily (0000 UTC) data on 23 vertical pressure levels from 1000 to $200 \mathrm{hPa}$, with the exception of diabatic heating, which is explicitly provided by ERA-Interim. The diabatic heating term is interpolated from hybrid sigma-pressure coordinates to pressure coordinates and is composed of longwave radiational heating (shortwave radiational heating is found to be negligible in the domains examined in this study), and the sum of latent heating and vertical mixing, where the sum of latent heating and vertical mixing is determined as in Part I [(5)], following Fueglistaler et al. (2009). We then repeat the analysis of this budget using diabatic heating provided by JRA-55, which includes separate values for the large-scale condensational heating, convective heating, and vertical mixing. These quantities are represented as daily means that are interpolated from a $1.25^{\circ} \times 1.25^{\circ}$ grid to a $2.5^{\circ} \times 2.5^{\circ}$ grid to match the resolution of the other variables.

As noted in Part I, the diabatic heating terms provided by ERA-Interim and JRA-55 are heavily dependent on the parameterization schemes that are used in the reanalysis and are thus likely to contain errors resulting from the misrepresentation of subgrid-scale processes.
Errors are particularly likely for terms in (4) that depend on cloud parameterizations, such as latent heating and radiative heating rates. For example, Prenni et al. (2007) showed that the misrepresentation of clouds by regional climate models likely causes large errors in surface DLR over the Arctic. However, as we will be discussed in section 3b, the ERA-Interim and JRA-55 diabatic heating datasets are consistent with each other, which gives us more confidence in the values of the diabatic heating data. Nevertheless, the reader is advised to consider possible shortcomings in the diabatic heating data.

The evolution of the temperature anomalies is given by

$$
\begin{aligned}
\frac{\partial T^{\prime}}{\partial t}= & \left(-\mathbf{u}^{\prime} \cdot \nabla \bar{T}+\overline{\mathbf{u}^{\prime} \cdot \nabla \bar{T}}\right)+\left(-\overline{\mathbf{u}} \cdot \nabla T^{\prime}+\overline{\overline{\mathbf{u}} \cdot \nabla T^{\prime}}\right) \\
& +\left(-\mathbf{u}^{\prime} \cdot \nabla T^{\prime}+\overline{\mathbf{u}^{\prime} \cdot \nabla T^{\prime}}\right)+(-\overline{\mathbf{u}} \cdot \nabla \bar{T}+\overline{\overline{\mathbf{u}} \cdot \nabla \bar{T}}) \\
& +\left[S_{p} \omega\right]^{\prime}+\left[\frac{\dot{Q}}{c_{p}}\right]^{\prime}+\operatorname{Res}^{\prime}
\end{aligned}
$$

where the primes denote the deviation from the smoothed seasonal cycle (see Part I for more details about the advection terms). Each term in (5) is composited and 


\section{RRTMG: Downward Longwave Radiation Anomalies}
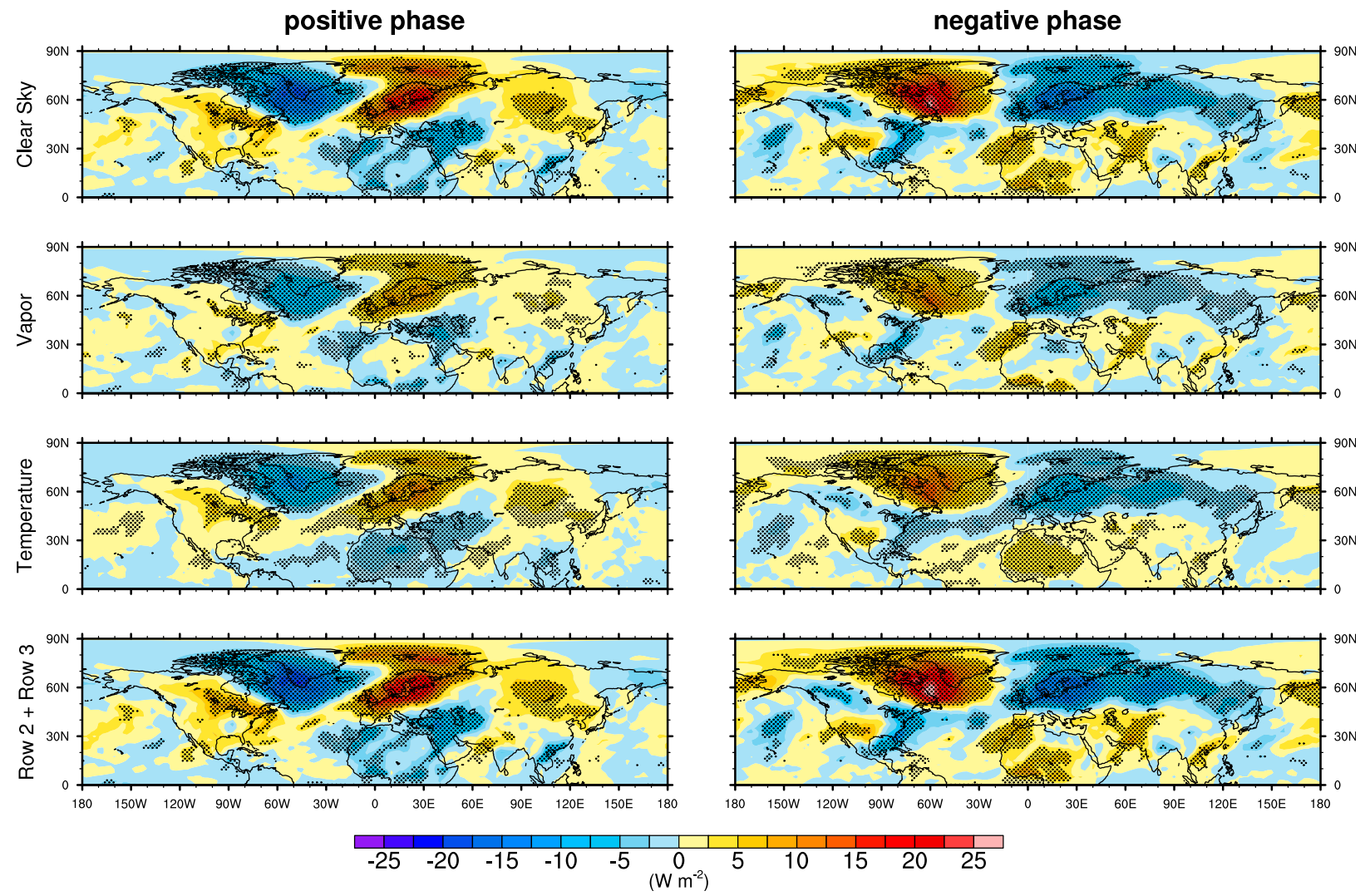

FIG. 2. (top) Composites of surface clear-sky downward longwave radiation anomalies, calculated using the Rapid Radiative Transfer Model (RRTMG; Iacono et al. 2008), for the (left) positive and (right) negative phases of the NAO. Also shown are the contribution to the clear-sky downward longwave radiation anomalies shown in the top row by (second row) water vapor anomalies and (third row) temperature anomalies, separated using the method described in section 2a. (bottom) The sum of the second and third rows. Stippling denotes statistical significance at $p<0.10$.

spatially averaged over the domains outlining the major anomalies in Fig. 1 (see Table 1 for the precise ranges). The individual terms on the rhs of (5) are then integrated forward in time on all vertical levels, similar to the manner outlined in Seo et al. (2016), with a time step of 1 day. The integrations are initiated at lag day -10 over Greenland and Europe and at lag day -5 over the United States and North Africa (at grid points above the surface).

\section{c. Total column water budget equation}

To further understand the processes that drive the surface DLR anomalies of the NAO, in particular, the contribution to the surface DLR anomalies by clouds and water vapor, a TCW budget equation is examined:

$$
\frac{1}{g} \frac{\partial}{\partial t}\left[\int_{0}^{p_{s}} W d p\right]^{\prime}=E^{\prime}-P^{\prime}-\left[\frac{1}{g} \int_{0}^{p_{s}} \nabla \cdot(\mathbf{u} W) d p\right]^{\prime}+\mathrm{Res}^{\prime},
$$

where the residual includes the surface boundary term (e.g., Seager and Henderson 2013), numerical error, horizontal diffusion (which is included in the reanalysis model), and an analysis increment (e.g., Trenberth et al. 2011). This form of the water budget equation states that the anomalous TCW (left-hand side) can be altered through changes in the anomalous evaporation $E^{\prime}$, precipitation $P^{\prime}$, and the vertical integral of water flux convergence $\left[(1 / g) \int_{0}^{p_{s}} \nabla \cdot(\mathbf{u} W) d p\right]^{\prime}$. Each term in (6) is explicitly provided in some form by the ERAInterim dataset, with the exception of processes included in the residual term.

TABLE 1. Domains of the major temperature anomalies.

\begin{tabular}{lc}
\hline \multicolumn{1}{c}{ Region } & \multicolumn{1}{c}{ Domain } \\
\hline Greenland and Baffin Bay & $55^{\circ}-85^{\circ} \mathrm{N}, 20^{\circ}-75^{\circ} \mathrm{W}$ \\
Europe and the Barents and Kara Seas & $45^{\circ}-85^{\circ} \mathrm{N}, 5^{\circ} \mathrm{W}-60^{\circ} \mathrm{E}$ \\
United States & $30^{\circ}-50^{\circ} \mathrm{N}, 75^{\circ}-110^{\circ} \mathrm{W}$ \\
Northern Africa & $5^{\circ}-35^{\circ} \mathrm{N}, 10^{\circ} \mathrm{W}-30^{\circ} \mathrm{E}$ \\
\hline
\end{tabular}


TABLE 2. Domain-averaged surface downward longwave radiation anomalies $\left(\mathrm{W} \mathrm{m}^{-2}\right)$.

\begin{tabular}{|c|c|c|c|c|c|}
\hline \multirow[b]{2}{*}{ Region } & \multicolumn{2}{|c|}{ ERA-Interim } & \multicolumn{3}{|c|}{ RRTMG } \\
\hline & All sky & Clear sky & Clear sky & Water vapor & Temperature \\
\hline \multicolumn{6}{|c|}{ Positive NAO } \\
\hline Greenland and Baffin Bay & -14.48 & -10.92 & -10.54 & -5.07 & -6.17 \\
\hline Europe and the Barents and Kara Seas & 9.51 & 7.50 & 7.02 & 3.41 & 3.92 \\
\hline United States & 4.20 & 4.12 & 3.61 & 1.57 & 2.52 \\
\hline Northern Africa & -3.30 & -3.78 & -3.22 & -0.78 & -2.52 \\
\hline \multicolumn{6}{|c|}{ Negative NAO } \\
\hline Greenland and Baffin Bay & 12.98 & 12.02 & 11.42 & 5.06 & 7.33 \\
\hline Europe and the Barents and Kara Seas & -9.33 & -7.74 & -7.29 & -3.29 & -4.44 \\
\hline United States & -1.97 & -1.76 & -0.98 & -0.83 & -0.14 \\
\hline Northern Africa & 3.30 & 3.77 & 3.33 & 1.01 & 2.47 \\
\hline
\end{tabular}

To examine this budget, 6-hourly data of TCW, water flux convergence, evaporation and precipitation are composited. Then each term is integrated forward in time from lag day -15 to lag day +15 at each grid point with a 6-h time step. Note that the lag at which the water budget integration is initiated is different from the lag at which thermodynamic budget integration is initiated because, unlike the thermodynamic budget integration, the water budget integration has a small residual term even when initiated at early lags.

It is important to note here as well, that the evaporation and precipitation terms in the water budget equation are also strongly dependent on the parameterization schemes used in reanalysis models and, as such, are likely to contain errors. In fact, the values of TCW can vary among different reanalyses (Schröder et al. 2016), suggesting that the results to be presented in this study may be somewhat dependent on the dataset that is used. Nevertheless, for January precipitation, for a station within the NAO region, Weedon et al. (2014) found a good match between the ERA-Interim data and both Climate Research Unit (CRU) and Global Precipitation Climatology Project (GPCP) data. Similarly, for synopticscale cloud cover at the same location, Weedon et al. (2014) found good agreement between ERA-Interim data and observations. In addition, Balsamo et al. (2015) found that the ERA-Interim precipitation is close to that of GPCP within the extratropics.

\section{Results}

\section{a. Radiative transfer calculations}

Figure 1 displays the ERA-Interim surface DLR anomaly pattern associated with the NAO, which, for both NAO phases, is characterized by four pronounced anomalies, consistent with previous findings (e.g., Gong and Luo 2017; Luo et al. 2017, 2019). However, it has not been previously noted (to the best of our knowledge) that the all-sky surface DLR anomaly pattern of the NAO can be explained mostly by clear-sky surface DLR, as evidenced by the similarity in the spatial pattern and amplitude of the anomalies in the first two rows of Fig. 1. In fact, the difference between the all-sky and clear-sky surface DLR anomaly composites, shown in the third row of Fig. 1, suggests that the effect of clouds on the NAO's surface DLR anomalies is mainly confined to the Arctic and is small relative to the contribution by clear-sky surface DLR. Clouds, however, do amplify the surface DLR anomaly pattern of the NAO, consistent with the findings of Trigo et al. (2002). Specifically, the difference shown in the third row of Fig. 1 indicates that clouds amplify the surface DLR anomalies in the vicinity of Greenland and Europe.

A decomposition of the clear-sky surface DLR anomaly pattern using (2) and (3) is shown in Fig. 2. Conceptually, row 2 of Fig. 2 can be thought of as the first term on the rhs of (1) while row 3 of Fig. 2 can be thought of as the second term on the rhs of (1). Recall that the reanalysis clear-sky values shown in Fig. 1 represent 24-h accumulated daily averages (see Part I) whereas the RRTMG calculations shown in Fig. 2 represent instantaneous values at 0000 UTC. Therefore, although the match between row 1 of Fig. 2 and row 2 of Fig. 1 is not perfect, the match is good enough to justify our use of RRTMG. Further justification for the use of RRTMG is provided in the supplemental material.

The results shown in Fig. 2 suggest that water vapor and temperature anomalies have approximately equal contributions to the clear-sky surface DLR anomaly pattern of the NAO, particularly over high latitudes. However, over low-latitude regions (North Africa and the eastern United States), the contribution by temperature anomalies toward the clear-sky surface DLR appears to be greater than that from the water vapor anomalies. In Table 2, we display the domain-averaged contributions to the surface DLR anomalies of the NAO 
by the all-sky and clear-sky anomalies from ERAInterim, and by the clear-sky, water vapor, and temperature anomalies from RRTMG. The values in Table 2 reiterate many of the conclusions summarized above.

The bottom row of Fig. 2 shows the summation of the temperature and water vapor anomaly contributions to the clear-sky surface DLR anomalies (i.e., row $2+$ row 3 of Fig. 2), which is very similar to the clear-sky surface DLR anomaly pattern of the NAO (Fig. 2, top row). The similarity between rows 1 and 4 in Fig. 2 validates the method that we have employed to separate the role of temperature and water vapor anomalies toward the clearsky surface DLR anomalies. Furthermore, the similarity between rows 1 and 4 in Fig. 2 suggests that the nonlinear term in (1) is small. Indeed, Fig. S4 (supplemental material) shows that the difference between rows 1 and 4 of Fig. 2 [which can conceptually be thought of as the nonlinear term in (1)] is substantially smaller than the linear terms (rows 2 and 3 of Fig. 2).

\section{b. Thermodynamic energy equation}

Following the finding above that temperature anomalies make an important contribution to the surface DLR anomalies of the NAO, in this subsection, the processes that drive the temperature anomalies of the positive NAO, throughout the atmospheric column, are examined. The analysis presented below is conducted for the positive phase of the NAO only, for the sake of brevity, but the conclusions hold as well for the negative phase of the NAO.

The evolution of the temperature anomalies over Greenland, Europe, the United States, and North Africa (see Table 1 and the boxes in Fig. 1) is shown in Fig. 3 as a function of lag day and pressure. Upon examination of Fig. 3, it is evident that the high-latitude anomalies over Greenland and Europe extend from the surface to upward of $300 \mathrm{hPa}$ at lag day 0 (Fig. 3, top row), whereas the anomalies that overlie the mid- and low-latitude regions are weaker and shallower. Specifically, the anomalies that overlie the United States and North Africa are confined mostly to below about $500 \mathrm{hPa}$.

An integration of the rhs of (5) is shown in the bottom row of Fig. 3, which matches well with the temperature anomalies shown in the top row of Fig. 3, thereby enabling us to determine the contribution of each term in (5) toward the temperature anomalies. Rows 2-5 of Fig. 3 respectively show the contributions to the temperature anomalies over each region by horizontal temperature advection, $S_{p} \omega$, horizontal temperature advection $+S_{p} \omega$, and diabatic heating.

Comparing the top row of Fig. 3 with the remaining rows of Fig. 3 leads to the following conclusions:
1) Horizontal temperature advection drives the anomalies over each region. For example, over Greenland, horizontal temperature advection contributes to a temperature change of at least $10 \mathrm{~K}$ near the surface between about lag day -5 and lag day +10 , whereas over Europe the contribution is less at about $4 \mathrm{~K}$, most of which takes place between lag day -2 and lag day +4 . Over the United States, the cooling that is observed between lag day -5 and lag day 0 is also caused by horizontal temperature advection along with the temperature maximum observed over the United States at lag day +2 .

2) The term $S_{p} \omega$ opposes horizontal temperature advection over each region, especially above $500 \mathrm{hPa}$, consistent with expectations based on the quasigeostrophic omega equation (e.g., Holton and Hakim 2013, p. 198; Vallis 2017, p. 192), as the vertical motion acts to maintain thermal wind balance. This cancellation is most clearly shown by the sum of the horizontal temperature advection and $S_{p} \omega$ (fourth row in Fig. 3), which makes a smaller contribution to temperature change than does the horizontal temperature advection alone, especially in the middle and upper troposphere.

3) Below about $700 \mathrm{hPa}$, horizontal temperature advection is opposed mainly by the sum of all diabatic heating terms (although less so for Europe), consistent with results presented in Part I, where it was shown that longwave radiative heating/cooling accounted for the decay of the temperature anomalies on the lowest reanalysis model level.

Because the temperature anomalies throughout the atmospheric column are driven primarily by horizontal temperature advection, as noted above, we conclude that the temperature-driven contribution to the surface DLR anomalies (third row of Fig. 2) is ultimately caused by horizontal temperature advection. However, because horizontal temperature advection is strongly opposed by diabatic processes, we also investigate each of the diabatic processes separately. In particular, it is of interest to understand the diabatic processes that drive the decay of the temperature anomalies because the processes that drive the decay of the temperature anomalies ultimately contribute to the decay of the surface DLR anomalies.

An examination of the terms that compose the diabatic heating shows important differences compared to what is seen at the level nearest to the surface (analyzed in Part I), where horizontal temperature advection is opposed primarily by the longwave heating/cooling. At levels farther above the surface, as shown in Fig. 4, the contribution to temperature change by the sum of the 

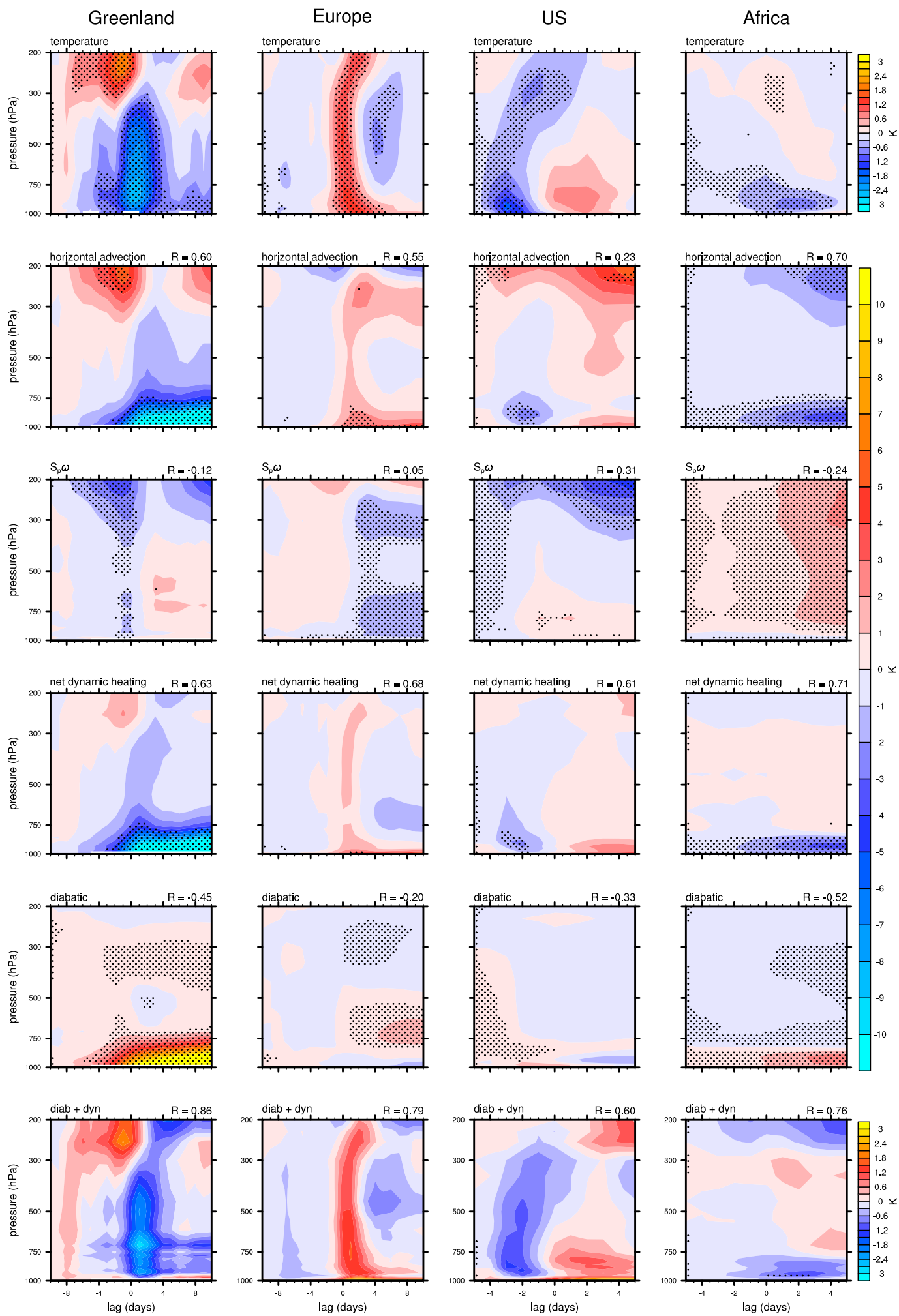

FIG. 3. (top) Vertical profile of temperature change over each region associated with the NAO (see columns). Also shown are the contributions to temperature change by (second to fifth rows) horizontal temperature advection, $S_{p} \omega$, $S_{p} \omega+$ horizontal temperature advection, and diabatic processes, respectively. (bottom) The sum of the fourth and fifth rows, which should theoretically be identical to the top row. The mass-weighted pattern correlation with the temperature change is shown in the top right of each panel. Statistical significance at $p<0.1$ is indicated by stippling. 

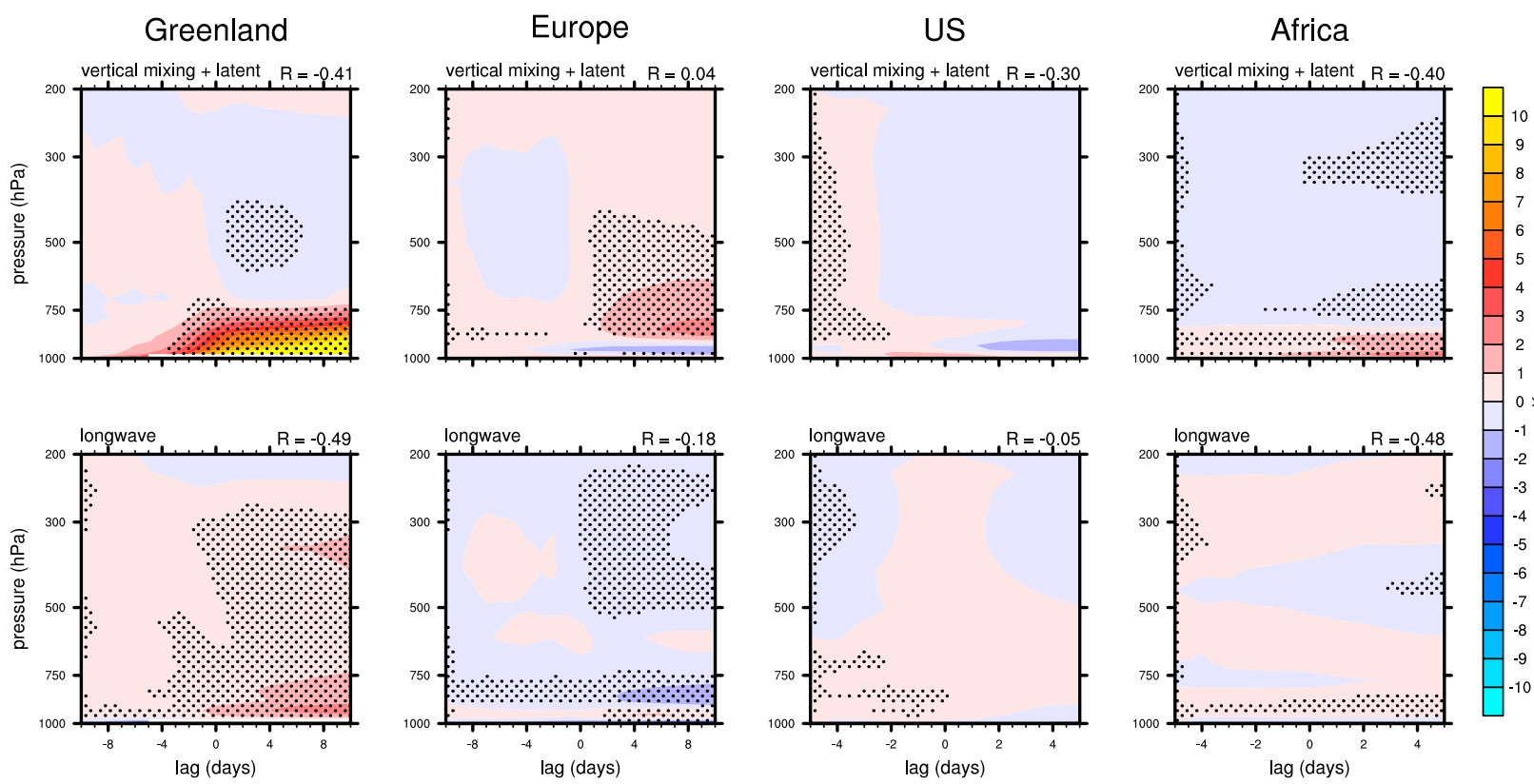

FIG. 4. Contributions to ERA-Interim diabatic heating by (top) vertical mixing + latent heat release and (bottom) longwave radiation. The mass-weighted pattern correlation with the temperature change is shown in the top right of each panel. Statistical significance at $p<$ 0.10 is indicated by stippling.

latent heating and vertical mixing is much larger than that by longwave heating/cooling.

We also examine the height dependence of longwave heating/cooling and vertical mixing + latent heat release on model levels (see Fig. 5). The vertical profiles in Fig. 5 are shown on model levels rather than on pressure levels because model level data can reveal details that cannot be seen in the relatively coarse-resolution data of pressure coordinates. Upon examination of Fig. 5, it is evident that longwave heating/cooling dominates the sum of latent heating and vertical mixing only over model levels very near the surface at $k=59$ and $k=60$ (the second-lowest and lowest model levels; altitudes indicated in the figure caption) over Greenland and Europe. At higher levels, vertical mixing dominates longwave heating/cooling. However, the vertical profiles over the United States and North Africa are more complicated. While it is beyond the scope of this study to precisely determine the processes that drive the regional and vertical variations in the longwave heating/cooling and vertical mixing terms over each region, we provide some plausible explanations.

To understand the vertical profiles of the anomalous longwave heating/cooling over each region, which usually peak near or at the lowest model level (Fig. 5), we hypothesize that emission of longwave radiation can be explained by the vertical profiles of climatological temperature and specific humidity, and anomalous temperature. Following the notation used for (1), this hypothesis can be understood if $-\bar{\varepsilon} \sigma T^{4}$ is taken to be the emission of longwave radiation within an atmospheric layer. For a small temperature anomaly $\Delta T$, the anomalous longwave heating/cooling can be approximated to first order by $-4 \bar{\varepsilon} \sigma \bar{T}^{3} \Delta T$. We expect the emission of longwave radiation to be maximum where $\bar{\varepsilon}$ and $\bar{T}$ are largest, while the sign of the emission of longwave radiation is determined by the sign of $\Delta T$. Over most regions, we find that the climatological specific humidity tends to maximize at the lowest model level (not shown), which suggests $\bar{\varepsilon}$ is also largest near the surface, and the largest values of $\bar{T}$ occurs between levels 56 and 59 (not shown). Also, it is found that the sign of $\Delta T$ is the opposite to that of the longwave heating/cooling at all levels for three of the four domains, the exception being the United States, where the anomalies are much smaller (not shown). These findings suggest that the vertical structure of the longwave heating/cooling in Fig. 5 can be understood from the vertical profiles of $\bar{\varepsilon}, \bar{T}$, and $\Delta T$.

In Figs. 4 and 5, it is unclear whether the sum of vertical mixing and latent heat release is dominated by latent heating or vertical mixing. Because ERA-Interim does not separately store latent heat release and vertical mixing, we cannot compare latent heat release and vertical mixing with that dataset. However, this question can be addressed with JRA-55 data, since that reanalysis dataset does provide separate daily values of vertical mixing, convective heating and large-scale condensational 


\section{Lag Day Zero Composite}
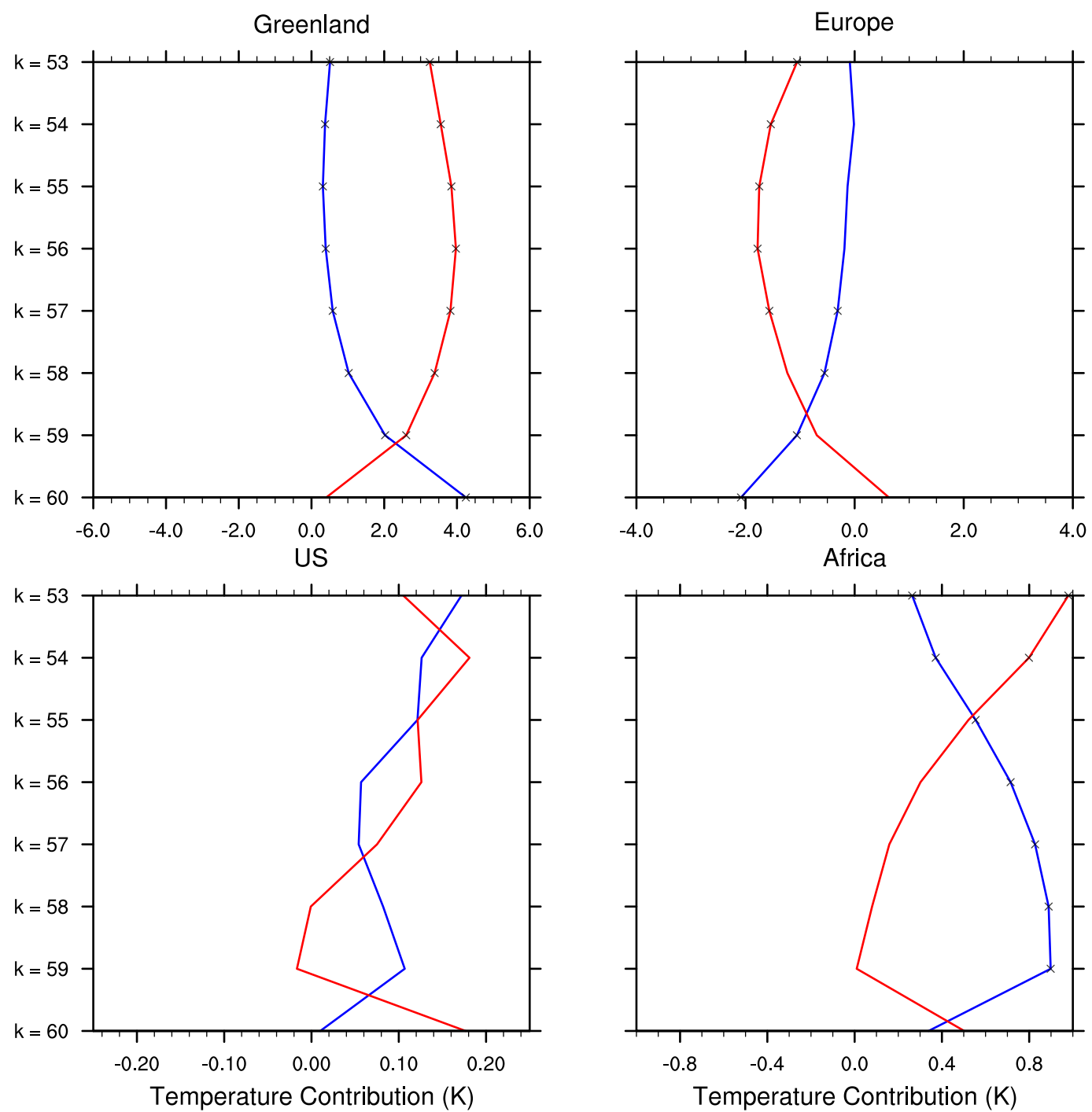

FIG. 5. The contribution to temperature change ( $x$ axis) by longwave heating/cooling (blue) and the sum of latent heat release with vertical mixing (red) at different model levels ( $y$ axis) at lag day 0 of the positive NAO. The level nearest to the surface, $k=60$, corresponds to an altitude of about $10 \mathrm{~m}$. Levels $59-53$ correspond to altitudes of approximately 30, 60, 100, 160, 240, 340, and $460 \mathrm{~m}$. See Table 2 of Berrisford et al. (2009) for more details. Statistical significance at $p<0.10$ is marked with $\times$.

heating. Comparison between ERA-Interim and JRA-55 diabatic heating terms shows that the sum of latent heating and vertical mixing is very similar between the two datasets (cf. Fig. 4, top row, and Fig. 6, bottom row). This result gives us confidence that JRA-55 data can be used to determine the separate contributions from vertical mixing and latent heat release for the temperature changes associated with the NAO.

The contribution to temperature change by each of these three diabatic heating terms (condensational heating, convective heating, and vertical mixing), as well as their sum, is shown in Fig. 6, from which we can see that the vertical mixing is the dominant diabatic process contributing to the decay of the temperature anomalies, because of cancellation between the convective and largescale condensational heating (cf. the third and fourth rows of Fig. 6). However, over Europe, it should be noted that the diabatic heating appears to be dominated by the sum of convective and large-scale condensational heating (cf. the first, second, and fourth rows of Fig. 6).

The vertical profiles of the strength of the vertical mixing for the different regions in Fig. 5 may depend in 

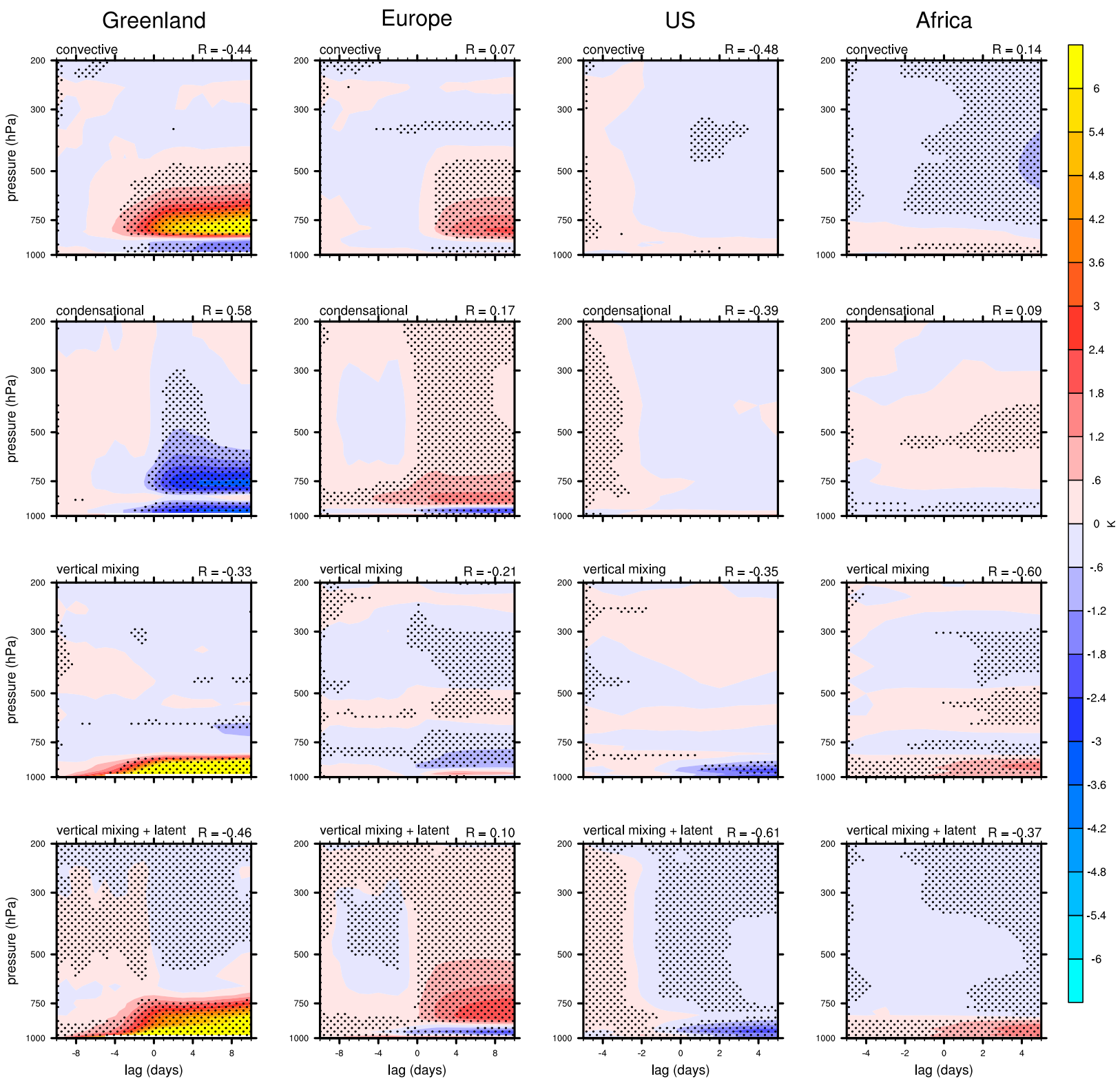

FIG. 6. The contribution to latent heat release + vertical mixing by (top) convective heating, (second row) condensational heating, and (third row) vertical mixing according to the Japanese Meteorological Agency Reanalysis dataset. (bottom) The sum of the first three rows. The mass-weighted pattern correlation with the temperature change is shown in the top right of each panel. Statistical significance at $p<$ 0.10 is indicated by stippling.

part on the static stability and vertical wind shear, as these quantities can impact the Richardson number. Therefore, we investigated the vertical profile of both temperature and wind shear (not shown) and found that the daily mean vertical temperature profile is stable near the surface over all four regions, especially over Greenland and Europe where a strong inversion is present during both day and night in the winter. This can explain why mixing is weakest at the lowest model level over Greenland and Europe. However, over North Africa, mixing is stronger near the surface likely because we find that the nighttime inversion over this region breaks during the daytime (not shown), allowing for the development of stronger vertical mixing. Consistently, we find that the boundary layer depth over North Africa is much greater in the daytime than during nighttime (not shown). Overall, we conceptualize the above finding that vertical mixing contributes to the decay of the temperature anomalies in Figs. 4 and 5 by considering flux-gradient theory (see Part I), where 
Greenland
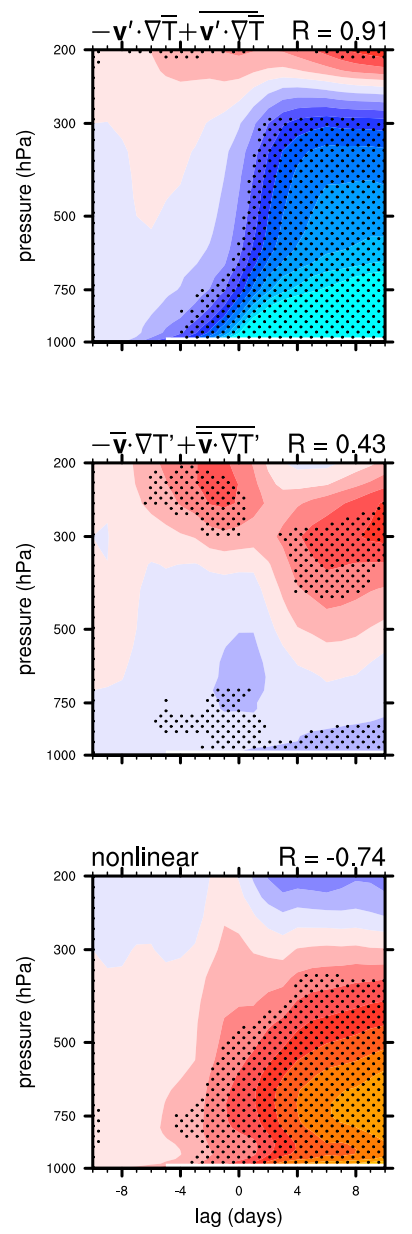

Europe
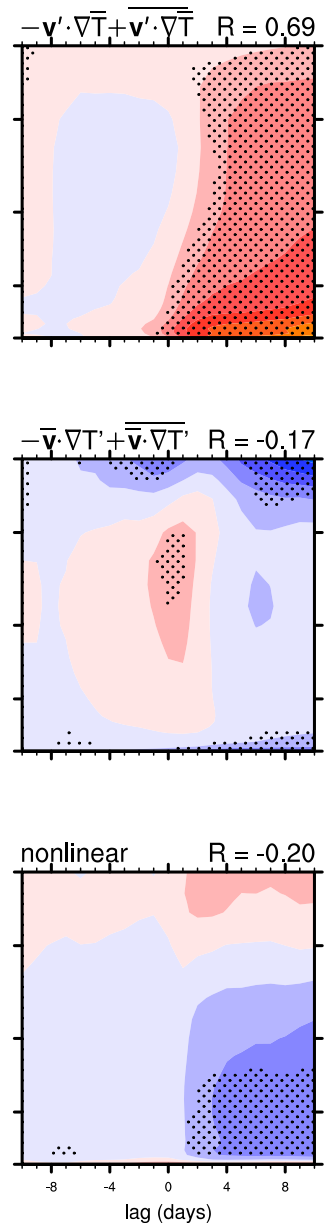

US
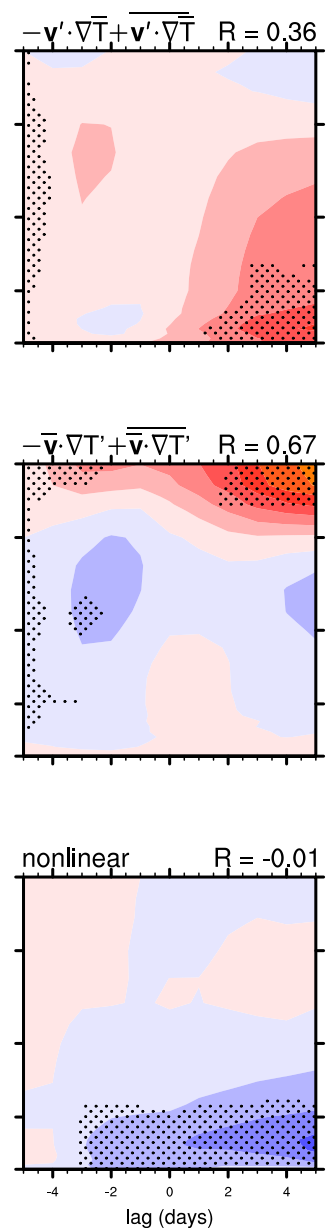

Africa

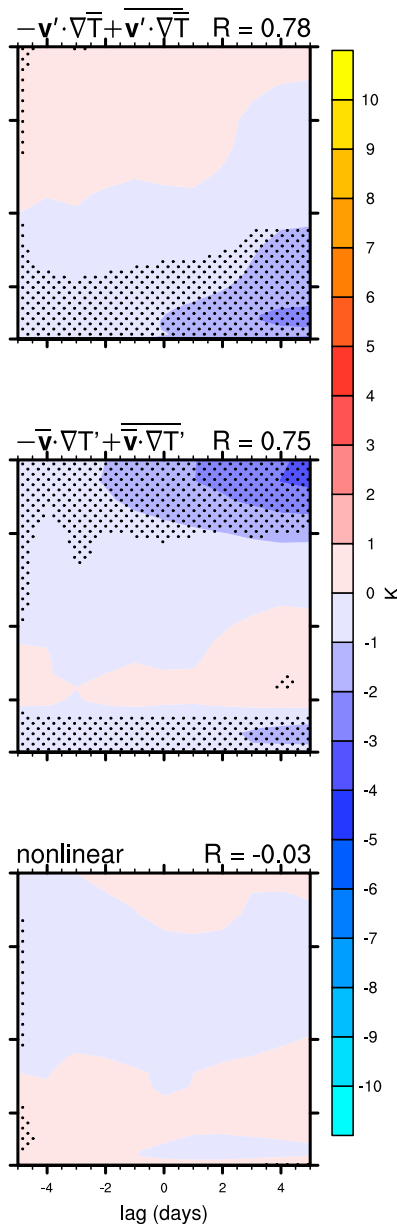

FIG. 7. The contribution to temperature change by (top) advection of climatological temperature by the anomalous wind, (middle) advection of anomalous temperature by the climatological wind, and (bottom) advection of anomalous temperature by anomalous wind. The mass-weighted pattern correlation in the top right of each panel is with the total advection anomaly, i.e., the sum of all rows. Statistical significance at $p<0.10$ is indicated by stippling.

the vertical mixing is treated as being proportional to $\partial^{2} \theta / \partial z^{2}$, where $\theta$ is a time-averaged potential temperature and $z$ is height. An examination of the sign of $\partial^{2} \theta / \partial z^{2}$ composited over each of the four regions as a function of height (not shown) supports the above conceptualization.

To conclude our examination of the thermodynamic energy budget, in Figs. 7 and 8, we consider the different terms (derived in Part I) that compose anomalous horizontal temperature advection, because it is of interest to determine whether the surface DLR anomalies are driven by the anomalous wind field of the NAO. The terms that compose the anomalous horizontal temperature advection are 1) the advection of climatological temperature by the anomalous wind $\left.\left(-\mathbf{u}^{\prime} \cdot \nabla \bar{T}+\overline{\mathbf{u}^{\prime} \cdot \nabla \bar{T}}\right), 2\right)$ the advection of anomalous temperature by the climatological wind $\left.\left(-\overline{\mathbf{u}} \cdot \nabla T^{\prime}+\overline{\overline{\mathbf{u}} \cdot \nabla T^{\prime}}\right), 3\right)$ the advection of anomalous temperature by the anomalous wind $\left(-\mathbf{u}^{\prime} \cdot \nabla T^{\prime}+\overline{\mathbf{u}^{\prime} \cdot \nabla T^{\prime}}\right)$, and 4) a small term $(-\overline{\mathbf{u}} \cdot \nabla \bar{T}+\overline{\overline{\mathbf{u}} \cdot \nabla \bar{T}})$ that we omit from subsequent figures. Each of these terms uniquely contributes to the evolution of temperature anomalies of the NAO. We summarize their contributions below.

1) The advection of the climatological temperature by the anomalous wind makes the largest contribution to the anomalous horizontal temperature advection. Throughout most the atmospheric column, extending from the surface to about $300 \mathrm{hPa}$, the temperature anomalies associated with the NAO are produced by the circulation anomalies that characterize the NAO, consistent with presumptions of Wallace and Gutzler (1981) and the findings of Thompson and Wallace (2000). However, this finding seems to be inconsistent with Diao et al. (2015), who argue that the advection of the submonthly (7-31 day) temperature 


\section{Temperature Advection Composite}

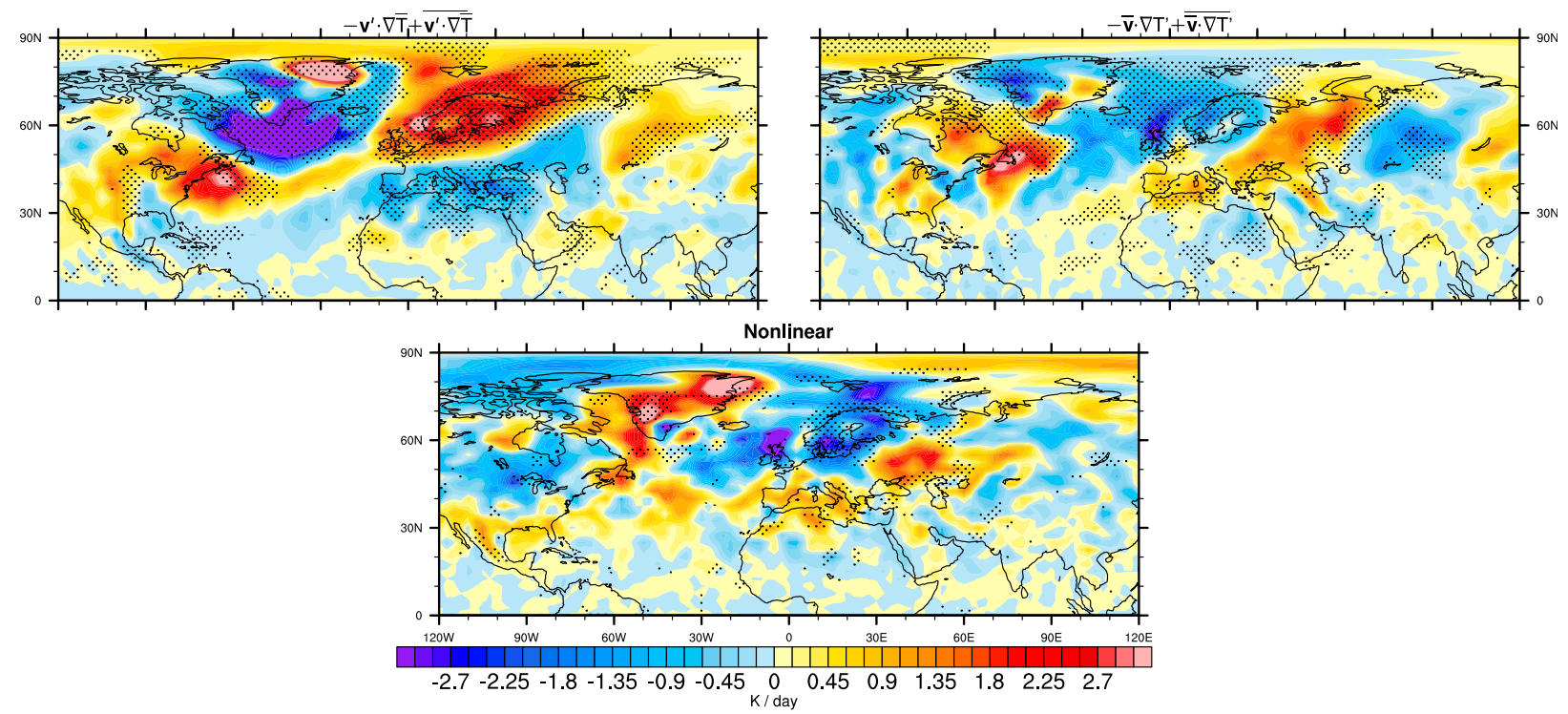

FIG. 8. Composites on lag day 0 of (top left) advection of climatological temperature by the anomalous wind, (top right) advection of anomalous temperature by the climatological wind, and (bottom) advection of anomalous temperature by the anomalous wind at $750 \mathrm{hPa}$, during the positive NAO. Statistical significance at $p<0.10$ is indicated by stippling.

anomalies by the submonthly wind anomalies drives the NAO's surface air temperature anomalies. Nonetheless, we find the quantity $\left(-\mathbf{u}^{\prime} \cdot \nabla \bar{T}+\overline{\mathbf{u}^{\prime} \cdot \nabla \bar{T}}\right)$ (Fig. 7, top row) to be greater than $(-\mathbf{u} \cdot \nabla T+\overline{\mathbf{u} \cdot \nabla T})$ (Fig. 3, second row) suggesting that one or more of the other horizontal temperature advection terms must oppose the quantity $\left(-\mathbf{u}^{\prime} \cdot \nabla \bar{T}+\overline{\mathbf{u}^{\prime} \cdot \nabla \bar{T}}\right)$.

2) The nonlinear term, that is, the advection of anomalous temperature by the anomalous wind $\left(-\mathbf{u}^{\prime} \cdot \nabla T^{\prime}+\overline{\mathbf{u}^{\prime} \cdot \nabla T^{\prime}}\right)$ (Fig. 7, third row), shows strong opposition to the advection of the climatological temperature by the anomalous wind (Fig. 7, top row). This finding is consistent with several studies showing that transient eddy heat fluxes tend to damp zonal asymmetries in the horizontal temperature field of both stationary eddies (Lau and Wallace 1979; Lau and Holopainen 1984; Held et al. 2002) and lowfrequency anomalies (Pan et al. 2006). Throughout the troposphere, we find the anomaly patterns of $\left(-\mathbf{u}^{\prime} \cdot \nabla T^{\prime}+\overline{\mathbf{u}^{\prime} \cdot \nabla T^{\prime}}\right)$ and $\left(-\mathbf{u}^{\prime} \cdot \nabla \bar{T}+\overline{\mathbf{u}^{\prime} \cdot \nabla \bar{T}}\right)$ to be negatively correlated (supplemental material, Fig. S5).

3) The advection of the climatological temperature by the anomalous wind is characterized by a quadrupole pattern that projects positively onto the NAO's surface air temperature (SAT) anomaly pattern at lag day 0 (top-left panel of Fig. 8), which is expected based on the strength and direction of the winds relative to the climatological temperature gradient (e.g., Wallace and Gutzler 1981, their Fig. 1).
Consistent with Thompson and Wallace (2000), the quantity $\left(-\mathbf{u}^{\prime} \cdot \nabla \bar{T}+\overline{\mathbf{u}^{\prime} \cdot \nabla \bar{T}}\right)$ is dominated by the zonal component (Fig. S6).

4) In the upper troposphere and lower stratosphere (between 300 and $200 \mathrm{hPa}$, for all four regions), the advection of anomalous temperature by the climatological wind $\left(-\overline{\mathbf{u}} \cdot \nabla T^{\prime}+\overline{\overline{\mathbf{u}} \cdot \nabla T^{\prime}}\right)$ dominates horizontal temperature advection (cf. the second row of Fig. 7 and the second row of Fig. 3), perhaps because the climatological wind in the upper troposphere and lower stratosphere is sufficiently strong such that the contribution to advection by the anomalous wind is comparatively small.

5) The advection of anomalous temperature by the climatological wind (top-right panel of Fig. 8) causes warming downstream of the positive temperature anomalies and cooling downstream of the negative temperature anomalies. We schematically conceptualize this observation in Fig. 9.

In summary, the results of the thermodynamic energy budget reveal a variety of interesting relationships between horizontal temperature advection and the other terms in (5). First, in the lower troposphere, where the large-scale vertical air motions are presumably small, $S_{p} \omega$ is small and therefore the vertical mixing term opposes horizontal temperature advection. The exception is in the lower troposphere, at the level nearest to the surface, where, as shown in Part I, it is the longwave heating/cooling that opposes the horizontal temperature 


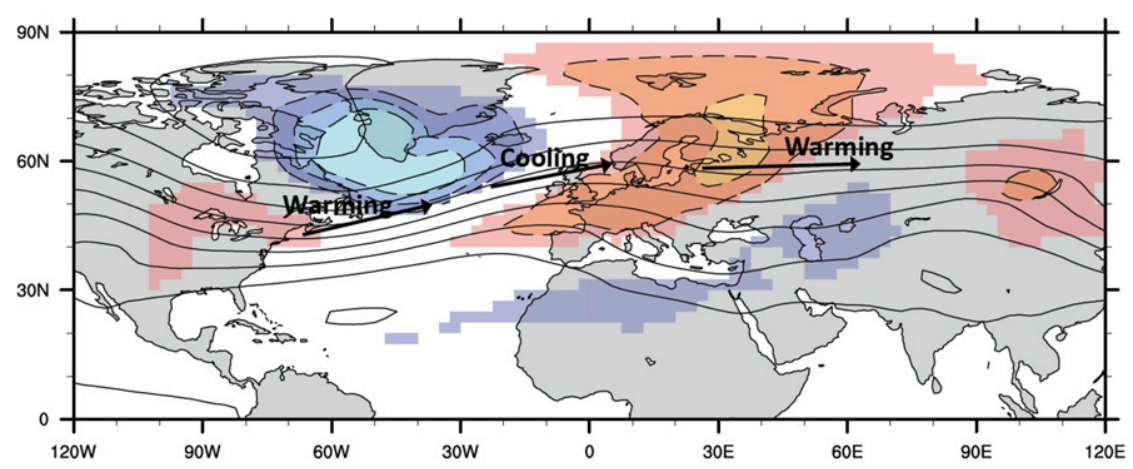

FIG. 9. Temperature anomaly composite on lag day 0 at $750 \mathrm{hPa}$ (colors) for the positive phase of the NAO, with the DJF climatology of geopotential height overlaid (solid lines). The sign of the impact of the advection is denoted by the words "Warming" or "Cooling."

advection. Second, in the middle and upper troposphere, where the large-scale vertical motions are not small, vertical mixing is relatively small and $S_{p} \omega$ opposes horizontal temperature advection, consistent with quasigeostrophic theory. Finally, throughout the entire troposphere, the nonlinear advection term opposes the advection of the climatological temperature by the anomalous wind. In spite of all of the opposing processes, horizontal temperature advection, which is driven by the NAO's anomalous wind field, dominates the temperature changes observed throughout the atmospheric column over each region. Therefore, the temperature-driven contribution to the surface DLR anomalies of the NAO (Fig. 2, third row) result primarily from the horizontal advection of climatologically warm/cold air by the anomalous wind field of the NAO.

\section{c. Total column water budget}

Having established that horizontal temperature advection drives the temperature anomalies that contribute to the NAO's surface DLR anomaly pattern, in this subsection, we examine the TCW budget equation [(6)] to determine the processes that give rise to the changes in TCW. As for the thermodynamic budget analysis, the TCW budget is examined for the positive phase of the NAO only, as the results are similar for the negative phase of the NAO.

A feature immediately apparent upon examination of the TCW anomaly pattern of the NAO (Fig. 10, left column) is its similarity with the surface DLR anomaly pattern of the NAO, especially over high latitudes, where magnitudes in excess of $2.5 \mathrm{~kg} \mathrm{~m}^{-2}$ are observed at lag day 0 . The pronounced TCW anomalies over high latitudes, shown in Fig. 10, are perhaps reflected in Fig. 2 (second row), which shows that water vapor's contribution to the surface DLR anomaly pattern of the NAO is more pronounced over high latitudes. The large TCW anomalies over high latitudes may also be reflected in
Fig. 1 (third row), which shows that clouds also amplify the surface DLR anomalies over high latitudes. To determine what drives the TCW anomalies, we separately examine each term in the TCW budget, which is justified by the fact that residual term is small (right column of Fig. 10).

Of all the terms on the rhs of (6), the water flux convergence has the strongest positive pattern correlation with TCW (cf. the pattern correlations displayed in the top left of each panel in Fig. 10), suggesting that the TCW anomaly pattern associated with the NAO is driven by water flux convergence, consistent with Gong and Luo (2017) and Luo et al. (2017). Interestingly, Luo et al. (2017) employed a back-trajectory analysis to show that most of the water vapor that is advected into Europe and Greenland originates over the North Atlantic Ocean.

Similar to the advection of climatological temperature by the anomalous wind, the water flux convergence (second column in Fig. 10) depicts a quadrupole pattern, consistent with Liu and Barnes (2015). The quadrupole pattern of the water flux convergence shown in Fig. 10 perhaps reflects a driving by the anomalous wind field of the NAO. The integration of water flux convergence term leads to peak magnitudes of about $10-15 \mathrm{~kg} \mathrm{~m}^{-2}$ during the positive phase of the NAO off the East Coast of the United States, North Africa, and Europe, between lag day -15 and +15 , which is far greater than the change in TCW observed over the same regions. The fact that the integration of water flux convergence (Fig. 10, second column) leads to magnitudes far in excess of the TCW anomalies (Fig. 10, left column) indicates that there must be one or more processes in opposition to the water flux convergence such that the change in TCW is smaller.

From Fig. 10, it can be seen that the extreme values in water flux convergence are largely opposed by evaporation minus precipitation (fifth column in Fig. 10), such 


\section{Composites against the Positive NAO}
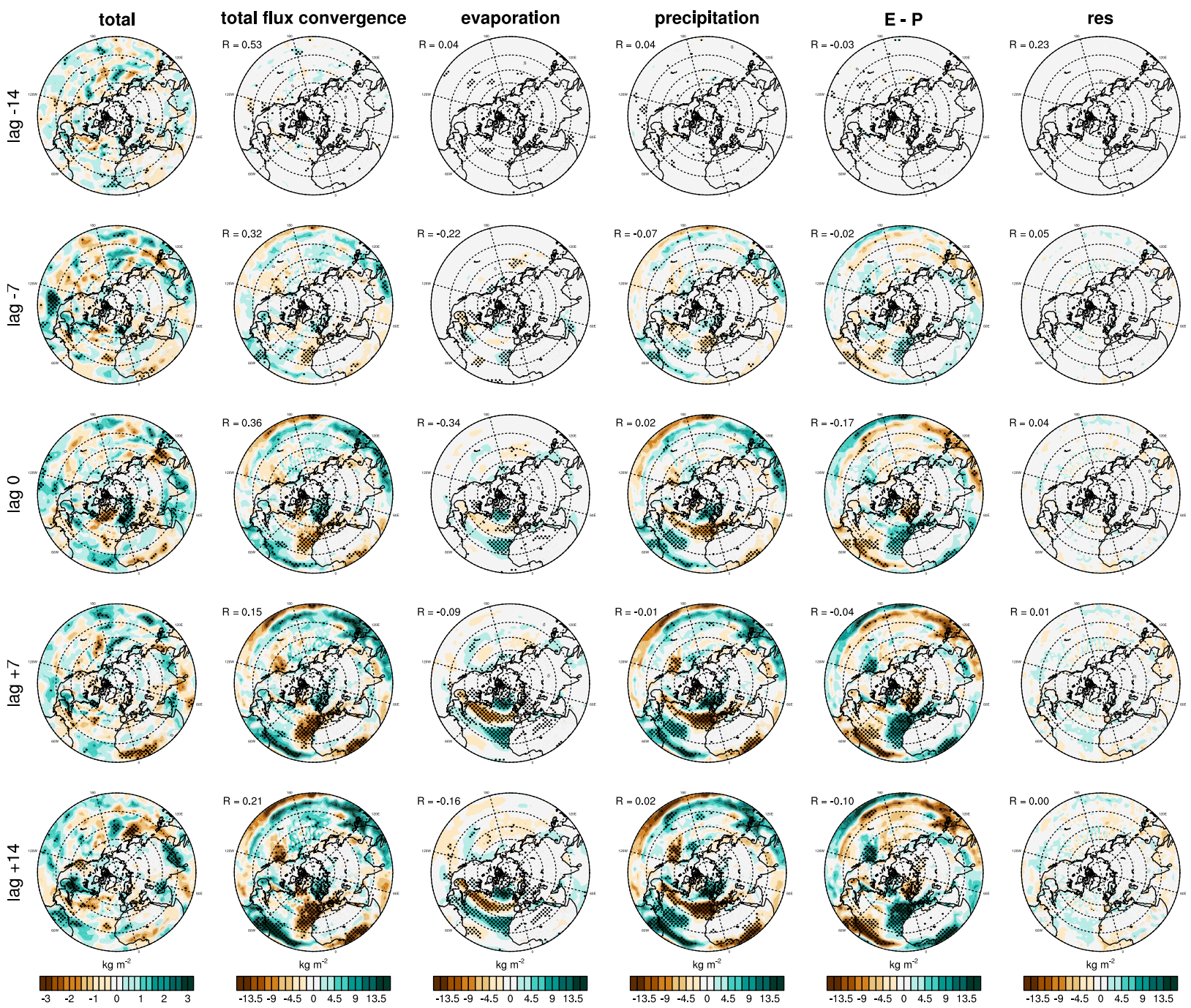

FIG. 10. (left) Composite TCW change as a function of lag day (see rows). Also shown are the contributions to TCW change by (second to fifth columns) water flux convergence, evaporation, precipitation, and evaporation minus precipitation, respectively. (right) The residual, i.e., the left column minus the sum of the second through fifth columns. The pattern correlation, weighted by the cosine of latitude, with the TCW change is shown in the top left of each panel. Statistical significance at $p<0.10$ is indicated by stippling.

that the TCW anomalies are comparatively small. This opposition is most apparent in Fig. 11, where the contributions from each term in the water budget are averaged over the four domains (Table 1). The relationship between the water flux convergence and evaporation minus precipitation appears rather reminiscent of the relationship between horizontal temperature advection and longwave heating/cooling shown to exist on the lowest model level in Part I of this study. That is, water flux convergence drives the growth of the TCW anomalies associated with the NAO, and evaporation minus precipitation is responsible for the decay of TCW anomalies. However, in Fig. 11 it is also evident that evaporation and precipitation are not equally important for returning the TCW to its climatological value. Over Europe and North Africa, evaporation is the process that drives the decay of the TCW anomaly, whereas over Greenland the decay of the TCW anomaly is driven by precipitation.

The processes that give rise to evaporation and precipitation changes shown in Figs. 10 and 11 are associated with the redistribution of atmospheric mass that characterizes the NAO. During the positive phase of the $\mathrm{NAO}$, the Icelandic low and Azores high are enhanced, leading to stronger westerlies, and therefore an eastward surface wind stress over the North Atlantic Ocean. In Fig. 10, we see that the evaporation alone (third column 


\section{Composites against the Positive NAO}
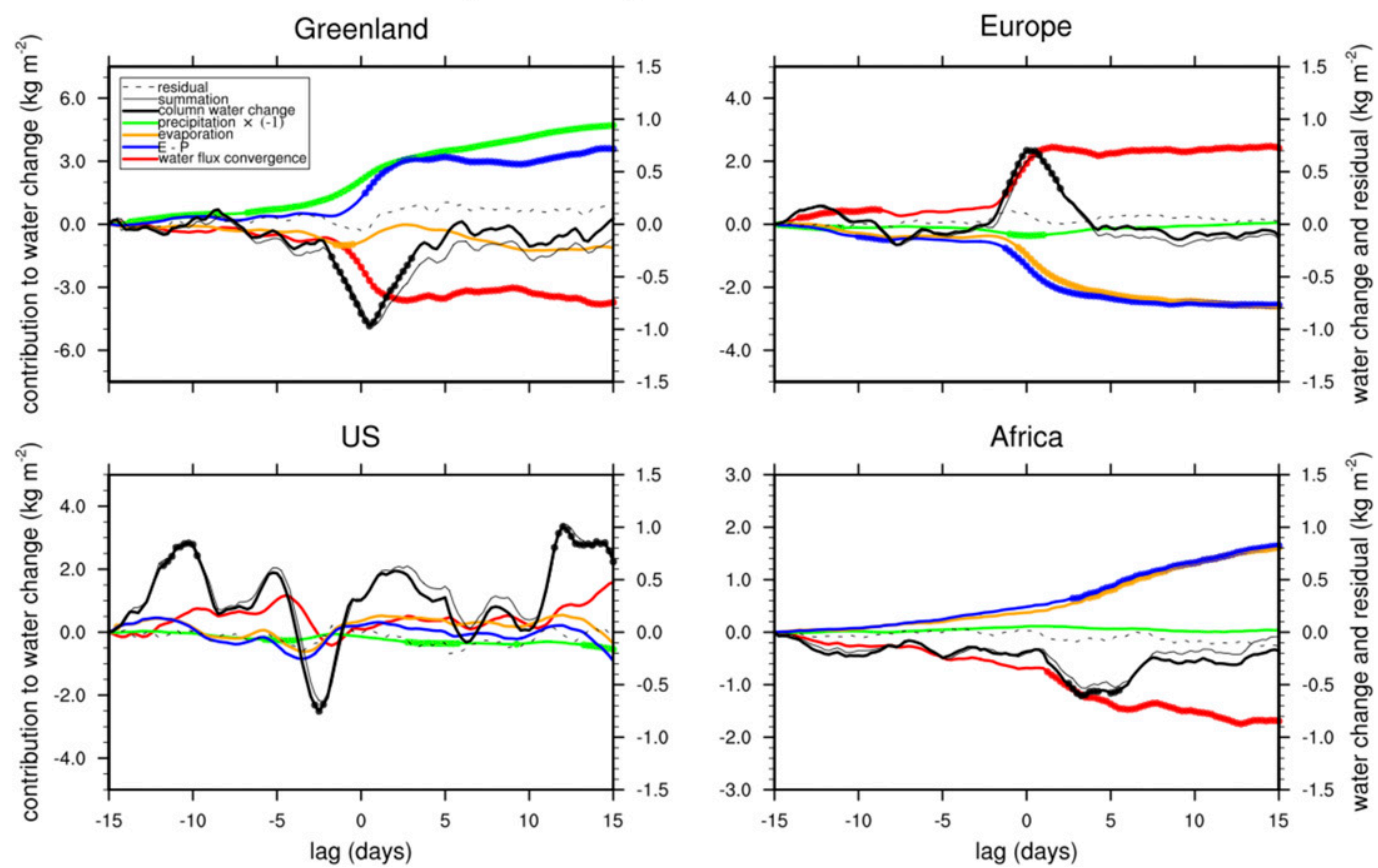

FIG. 11. The solid black line shows the TCW change, domain averaged over the region indicated by the title overlying each panel, which corresponds to the right axis. The green, red, blue, and orange lines show the contributions to the TCW change by precipitation (multiplied by -1), water flux convergence, precipitation, and evaporation minus precipitation, respectively. The thin black and dashed black lines show the sum of the colored lines and the residual term, respectively. Statistical significance at $p<0.10$ is indicated by thickened lines.

in Fig. 10) is suppressed over a zonal band extending from the East Coast of the United States to the southwestern coast of Europe and enhanced over the subtropical North Atlantic and within the Arctic Circle, consistent with what is expected based on the surface wind field that is observed when the NAO is in the positive phase. The poleward shift of the jet, associated with the NAO, is also likely responsible for changes in precipitation over the surrounding continents via the steering of synoptic-scale storms (e.g., Grise et al. 2013). In addition, Trigo et al. (2002) note that the precipitation fields of the NAO tend to be collocated with the vorticity fields.

\section{Summary and conclusions}

The results of this study show that a rich variety of processes involving changes in tropospheric temperature and water contribute to the driving of the NAO's skin temperature anomalies through changes in surface DLR. Following the finding that most of the all-sky surface DLR anomalies of the NAO can be explained by the clear-sky surface DLR contribution, clear-sky radiative transfer calculations were conducted using RRTMG. The RRTMG calculations indicate that temperature and water vapor anomalies contribute approximately equally to the NAO's clear-sky surface DLR anomaly pattern, especially over high-latitude regions, prompting an investigation into the drivers of the TCW and temperature anomalies.

The mechanisms that drive the atmospheric temperature and TCW anomalies associated with the NAO are investigated using the thermodynamic energy and water budget equations. Investigation of the dominant terms in these budget equations, based on composite analysis, reveals the processes that are responsible for the growth and decay of the temperature (at various pressure levels) and TCW anomalies during a typical NAO event. The temperature changes observed throughout the atmospheric column when the NAO is active are ultimately wind driven. Specifically, the advection of the climatological temperature field by the anomalous wind drives the NAO's temperature anomaly pattern throughout the troposphere. This result is consistent with presumptions of previous studies based on sea level pressure anomaly maps (e.g., Wallace and Gutzler 1981) and also with results from Thompson and Wallace (2000). Over each of the four domains (Table 1), water flux convergence is responsible for the growth of the TCW anomalies and, depending on the region, either evaporation or precipitation is responsible for the decay of the TCW anomalies. 
Specifically, evaporation drives the decay of the TCW anomaly over North Africa and Europe, whereas over Greenland, precipitation drives the decay of the TCW anomaly.

Apart from determining the ultimate driver to temperature changes in the atmospheric column, the composite analysis of the thermodynamic energy equation reveals a variety of other processes that oppose horizontal temperature advection. Specifically, near the surface, it is found that vertical mixing, in particular, opposes horizontal temperature advection, consistent with expectations based on flux-gradient theory. In the middle and upper troposphere, where the vertical velocity is not small, adiabatic warming/cooling opposes horizontal temperature advection more strongly than do the diabatic heating terms. Together, these opposing processes cause the temperature anomalies to decay after the NAO reaches its peak.

The decomposition of the anomalous horizontal temperature advection also gleans important details. The first of which is that the advection of anomalous temperature by anomalous wind, which we refer to as nonlinear temperature advection, opposes the advection of climatological temperature by the anomalous wind. Second, the advection of anomalous temperature by the climatological wind is also shown to be the most important contributor to temperature changes in the upper troposphere and lower stratosphere during a typical NAO event.

Acknowledgments. This study benefitted greatly from discussions with Dr. Eugene Clothiaux, who helped the authors configure RRTMG and understand preliminary radiative transfer results. In addition, we thank two anonymous reviewers for their helpful comments and suggestions, Paul Berrisford (ECMWF) for providing helpful resources regarding the water and thermodynamic energy budgets examined in this study, and Mingyu Park for downloading and preparing the JRA-55 data used in this study. This study was supported by National Science Foundation Grants OPP-1723832 and AGS-1822015.

\section{REFERENCES}

Balsamo, G., and Coauthors, 2015: ERA-Interim/Land: A global land surface reanalysis data set. Hydrol. Earth Syst. Sci., 19, 389-407, https://doi.org/10.5194/hess-19-389-2015.

Barnston, A. G., and R. E. Livezey, 1987: Classification, seasonality and persistence of low-frequency atmospheric circulation patterns. Mon. Wea. Rev., 115, 1083-1126, https://doi.org/10.1175/ 1520-0493(1987)115<1083:CSAPOL > 2.0.CO;2.

Benedict, J. J., S. Lee, and S. B. Feldstein, 2004: Synoptic view of the North Atlantic Oscillation. J. Atmos. Sci., 61, 121-144, https:// doi.org/10.1175/1520-0469(2004)061<0121:SVOTNA > 2.0.CO;2.

Berrisford, P., D. Dee, K. Fielding, M. Fuentes, P. Kallberg, S. Kobayashi, and S. Uppala, 2009: The ERA Interim archive:
Version 1.0. ECMWF Rep., 16 pp., http://ecmwf.int/publications/ library/do/references/show?id=89203.

Clark, J. P., and S. B. Feldstein, 2019: What drives the North Atlantic Oscillation's temperature anomaly pattern? Part I: The growth and decay of the surface air temperature anomalies. J. Atmos. Sci., 77, 185-198, https://doi.org/10.1175/ JAS-D-19-0027.1.

Dee, D. P., and Coauthors, 2011: The ERA-Interim reanalysis: Configuration and performance of the data assimilation system. Quart. J. Roy. Meteor. Soc., 137, 553-597, https://doi.org/ 10.1002/qj.828.

Diao, Y., S. P. Xie, and D. Luo, 2015: Asymmetry of winter European surface air temperature extremes and the North Atlantic Oscillation. J. Climate, 28, 517-530, https://doi.org/10.1175/ JCLI-D-13-00642.1.

Francis, J. A., and E. Hunter, 2006: New insight into the disappearing Arctic sea ice. Eos, Trans. Amer. Geophys. Union, 87, 509-511, https://doi.org/10.1029/2006EO460001.

Franzke, C., S. Lee, and S. B. Feldstein, 2004: Is the North Atlantic Oscillation a breaking wave? J. Atmos. Sci., 61, 145-160, https:// doi.org/10.1175/1520-0469(2004)061<0145:ITNAOA > 2.0.CO;2.

Fueglistaler, S., B. Legras, A. Beljaars, J. J. Morcrette, A. Simmons, A. M. Tompkins, and S. Uppala, 2009: The diabatic heat budget of the upper troposphere and lower/mid stratosphere in ECMWF reanalyses. Quart. J. Roy. Meteor. Soc., 135, 21-37, https://doi.org/10.1002/qj.361.

Gong, T., and D. Luo, 2017: Ural blocking as an amplifier of the Arctic sea ice decline in winter. J. Climate, 30, 2639-2654, https://doi.org/10.1175/JCLI-D-16-0548.1.

_, S. B. Feldstein, and S. Lee, 2017: The role of downward infrared radiation in the recent Arctic winter warming trend. J. Climate, 30, 4937-4949, https://doi.org/10.1175/ JCLI-D-16-0180.1.

Grise, K. M., S. W. Son, and J. R. Gyakum, 2013: Intraseasonal and interannual variability in North American storm tracks and its relationship to equatorial Pacific variability. Mon. Wea. Rev., 141, 3610-3625, https://doi.org/10.1175/mwr-d-12-00322.1.

Held, I. M., M. Ting, and H. Wang, 2002: Northern winter stationary waves: Theory and modeling. J. Climate, 15, 2125-2144, https:// doi.org/10.1175/1520-0442(2002)015<2125:NWSWTA > 2.0.CO;2.

Holton, J. R., and G. H. Hakim, 2013: An Introduction to Dynamic Meteorology. 5th ed. Academic Press, 532 pp.

Iacono, M. J., J. S. Delamere, E. J. Mlawer, M. W. Shephard, S. A. Clough, and W. D. Collins, 2008: Radiative forcing by longlived greenhouse gases: Calculations with the AER radiative transfer models. J. Geophys. Res., 113, D13103, https://doi.org/ 10.1029/2008JD009944.

Kobayashi, S., and Coauthors, 2015: The JRA-55 reanalysis: General specifications and basic characteristics. J. Meteor. Soc. Japan, $\mathbf{9 3}$, 5-48, https://doi.org/10.2151/jmsj.2015-001.

Lau, N. C., and J. M. Wallace, 1979: On the distribution of horizontal transports by transient eddies in the Northern Hemisphere wintertime circulation. J. Atmos. Sci., 36, 1844-1861, https:// doi.org/10.1175/1520-0469(1979)036<1844:OTDOHT>2.0.CO;2. , and E. O. Holopainen, 1984: Transient eddy forcing of the timemean flow as identified by geopotential tendencies. J. Atmos. Sci., 41, 313-328, https://doi.org/10.1175/1520-0469(1984)041<0313: TEFOTT $>2.0 . \mathrm{CO} ; 2$.

Liu, C., and E. A. Barnes, 2015: Extreme moisture transport into the Arctic linked to Rossby wave breaking. J. Geophys. Res. Atmos., 120, 3774-3788, https://doi.org/10.1002/2014jd022796.

Luo, B., D. Luo, L. Wu, L. Zhong, and I. Simmonds, 2017: Atmospheric circulation patterns which promote winter Arctic 
sea ice decline. Environ. Res. Lett., 12, 054017, https://doi.org/ 10.1088/1748-9326/aa69d0.

, L. Wu, D. Luo, A. Dai, and I. Simmonds, 2019: The winter midlatitude-Arctic interaction: Effects of North Atlantic SST and high-latitude blocking on Arctic Sea ice and Eurasian cooling. Climate Dyn., 52, 2981-3004, https://doi.org/10.1007/ s00382-018-4301-5.

Mlawer, E. J., S. J. Taubman, P. D. Brown, M. J. Iacono, and S. A. Clough, 1997: Radiative transfer for inhomogeneous atmospheres: RRTM, a validated correlated-k model for the longwave. J. Geophys. Res., 102, 16 663-16 682, https://doi.org/ 10.1029/97JD00237.

Pan, L. L., F. F. Jin, and M. Watanabe, 2006: Dynamics of synoptic eddy and low-frequency flow interaction. Part III: Baroclinic model results. J. Atmos. Sci., 63, 1709-1725, https://doi.org/ 10.1175/JAS3717.1.

Park, D.-S. R., S. Lee, and S. B. Feldstein, 2015: Attribution of the recent winter sea ice decline over the Atlantic sector of the Arctic Ocean. J. Climate, 28, 4027-4033, https://doi.org/10.1175/ JCLI-D-15-0042.1.

Park, H.-S., S. Lee, S. W. Son, S. B. Feldstein, and Y. Kosaka, 2015: The impact of poleward moisture and sensible heat flux on Arctic winter sea ice variability. J. Climate, 28, 5030-5040, https://doi.org/10.1175/JCLI-D-15-0074.1.

Prenni, A. J., and Coauthors, 2007: Can ice-nucleating aerosols affect Arctic seasonal climate? Bull. Amer. Meteor. Soc., 88, 541-550, https://doi.org/10.1175/BAMS-88-4-541.

Rivière, G., and I. Orlanski, 2007: Characteristics of the Atlantic storm-track eddy activity and its relation with the North Atlantic Oscillation. J. Atmos. Sci., 64, 241-266, https:// doi.org/10.1175/JAS3850.1.

Rogers, J. C., and H. van Loon, 1979: The seesaw in winter temperatures between Greenland and northern Europe. Part II: Some oceanic and atmospheric effects in middle and high latitudes. Mon. Wea. Rev., 107, 509-519, https://doi.org/10.1175/ 1520-0493(1979)107<0509:TSIWTB>2.0.CO;2.

Schröder, M., M. Lockhoff, J. M. Forsythe, H. Q. Cronk, T. H. Vonder Haar, and R. Bennartz, 2016: The GEWEX water vapor assessment: Results from intercomparison, trend, and homogeneity analysis of total column water vapor. J. Appl. Meteor. Climatol., 55, 1633-1649, https://doi.org/ 10.1175/JAMC-D-15-0304.1.

Seager, R., and N. Henderson, 2013: Diagnostic computation of moisture budgets in the ERA-Interim reanalysis with reference to analysis of CMIP-archived atmospheric model data. J. Climate, 26, 7876-7901, https://doi.org/10.1175/ JCLI-D-13-00018.1.
Seo, K. H., H. J. Lee, and D. M. Frierson, 2016: Unraveling the teleconnection mechanisms that induce wintertime temperature anomalies over the Northern Hemisphere continents in response to the MJO. J. Atmos. Sci., 73, 3557-3571, https:// doi.org/10.1175/JAS-D-16-0036.1.

Thompson, D. W., and J. M. Wallace, 2000: Annular modes in the extratropical circulation. Part I: Month-to-month variability. J. Climate, 13, 1000-1016, https://doi.org/10.1175/1520-0442(2000) 013<1000:AMITEC > 2.0.CO;2.

Trenberth, K. E., J. T. Fasullo, and J. Mackaro, 2011: Atmospheric moisture transports from ocean to land and global energy flows in reanalyses. J. Climate, 24, 4907-4924, https://doi.org/ 10.1175/2011JCLI4171.1.

Trigo, R. M., T. J. Osborn, and J. M. Corte-Real, 2002: The North Atlantic Oscillation influence on Europe: Climate impacts and associated physical mechanisms. Climate Res., 20, 9-17, https://doi.org/10.3354/cr020009.

Vallis, G. K., 2017: Atmospheric and Oceanic Fluid Dynamics. 2nd ed. Cambridge University Press, 946 pp.

van Loon, H., and J. C. Rogers, 1978: The seesaw in winter temperatures between Greenland and northern Europe. Part I: General description. Mon. Wea. Rev., 106, 296-310, https://doi.org/ 10.1175/1520-0493(1978)106<0296:TSIWTB >2.0.CO;2.

Walker, G. T., and E. W. Bliss, 1932: World weather V. Mem. Roy. Meteor. Soc., 4, 53-84.

Wallace, J. M., and D. S. Gutzler, 1981: Teleconnections in the geopotential height field during the Northern Hemisphere winter. Mon. Wea. Rev., 109, 784-812, https://doi.org/10.1175/ 1520-0493(1981)109<0784:TITGHF>2.0.CO;2.

Watanabe, M., 2004: Asian jet waveguide and a downstream extension of the North Atlantic Oscillation. J. Climate, 17, 46744691, https://doi.org/10.1175/JCLI-3228.1.

Weedon, G. P., G. Balsamo, N. Bellouin, S. Gomes, M. J. Best, and P. Viterbo, 2014: The WFDEI meteorological forcing data set: WATCH forcing data methodology applied to ERA-Interim reanalysis data. Water Resour. Res., 50, 7505-7514, https:// doi.org/10.1002/2014wr015638.

Woods, C., and R. Caballero, 2016: The role of moist intrusions in winter Arctic warming and sea ice decline. J. Climate, 29, 44734485, https://doi.org/10.1175/JCLI-D-15-0773.1.

$\_,-\frac{1}{-}$, and G. Svensson, 2013: Large-scale circulation associated with moisture intrusions into the Arctic during winter. Geophys. Res. Lett., 40, 4717-4721, https://doi.org/10.1002/grl.50912.

Woollings, T., B. Hoskins, M. Blackburn, and P. Berrisford, 2008: A new Rossby wave-breaking interpretation of the North Atlantic Oscillation. J. Atmos. Sci., 65, 609-626, https://doi.org/10.1175/ 2007JAS2347.1. 